ASTHMA

\title{
Tumour necrosis factor (TNF $\alpha$ ) as a novel therapeutic target in symptomatic corticosteroid dependent asthma
}

\author{
P H Howarth, K S Babu, H S Arshad, L Lau, M Buckley, W McConnell, P Beckett, \\ M Al Ali, A Chauhan, S J Wilson, A Reynolds, D E Davies, S T Holgate
}

See end of article for authors' affiliations (a)

Correspondence to: Professor S T Holgate, Infection, Inflammation and Repair Division, $\mathrm{F}$ Level South Block (810), Southampton General Hospital, Southampton SO16 6YD, UK; sth@ soton.ac.uk

Received 19 April 2005 Accepted 4 August 2005 Published Online First 15 September 2005

\begin{abstract}
Background: Tumour necrosis factor $\alpha(\mathrm{TNF} \alpha)$ is a major therapeutic target in a range of chronic inflammatory disorders characterised by a Th1 type immune response in which TNF $\alpha$ is generated in excess. By contrast, asthma is regarded as a Th2 type disorder, especially when associated with atopy. However, as asthma becomes more severe and chronic, it adopts additional characteristics including corticosteroid refractoriness and involvement of neutrophils suggestive of an altered inflammatory profile towards a Th1 type response, incriminating cytokines such as TNF $\alpha$.

Methods: TNF $\alpha$ levels in bronchoalveolar lavage (BAL) fluid of 26 healthy controls, 42 subjects with mild asthma and 20 with severe asthma were measured by immunoassay, and TNF $\alpha$ gene expression was determined in endobronchial biopsy specimens from 14 patients with mild asthma and 14 with severe asthma. The cellular localisation of TNF $\alpha$ was assessed by immunohistochemistry. An open label uncontrolled clinical study was then undertaken in 17 subjects with severe asthma to evaluate the effect of 12 weeks of treatment with the soluble TNF $\alpha$ receptor-lgG $F_{1}$ c fusion protein, etanercept.

Results: TNF $\alpha$ levels in BAL fluid, TNF $\alpha$ gene expression and TNF $\alpha$ immunoreative cells were increased in subjects with severe corticosteroid dependent asthma. Etanercept treatment was associated with improvement in asthma symptoms, lung function, and bronchial hyperresponsiveness.

Conclusions: These findings may be of clinical significance in identifying TNF $\alpha$ as a new therapeutic target in subjects with severe asthma. The effects of anti-TNF treatment now require confirmation in placebo controlled studies.
\end{abstract}

A sthma is a disorder of the conducting airways characterised by Th2 mediated inflammation, with recruitment of a range of inflammatory cells and enhanced mediator release. ${ }^{1}$ In mild disease the inflammatory response, attendant bronchial hyperresponsiveness (BHR), and variable airflow obstruction are highly responsive to inhaled corticosteroids, positioning these drugs as first line controller therapy for this disease. ${ }^{2}$ However, in persistent and severe asthma, inhaled corticosteroids are only partially effective, and patients often require intermittent or continuous oral corticosteroids. This severe end of the disease spectrum, which exhibits an altered inflammatory cell profile involving neutrophils ${ }^{3}{ }^{4}$ and accounts for approximately $10 \%$ of the asthmatic population, represents an important unmet clinical need as it is these patients who have the highest morbidity and mortality. ${ }^{5}$

Tumour necrosis factor $\alpha(\mathrm{TNF} \alpha)$ is a major therapeutic target in a range of chronic inflammatory disorders involving neutrophils. These include rheumatoid arthritis, juvenile arthritis, ankylosing spondylitis, Crohn's disease, psoriasis, glomerulonephritis, sarcoidosis and Behcet's disease, ${ }^{6}$ all of which are characterised by a Thl type immune response associated with excess generation of TNF $\alpha$. Although asthma is considered an eosinophilic disorder involving Th2 cytokines, ${ }^{1}$ there has been some interest in the TNF family of cytokines, especially TNF $\alpha$. In murine models of asthma, a deficiency in TNF $\alpha$ receptors, chronic treatment with a TNF $\alpha$ antibody, or induction of a TNF $\alpha$ autoantibody results in marked attenuation of antigen induced airway inflammation. ${ }^{78}$ Genetic association studies have also shown a strong association between TNF $\alpha$ gene polymorphism and $\mathrm{BHR}^{9}$ and asthma $^{10}$ and inhalation of TNF $\alpha$ in both rodents ${ }^{11}$ and normal or asthmatic humans ${ }^{12}{ }^{13}$ leads to the development of BHR accompanied by airway neutrophilia. Many different cell types produce $\mathrm{TNF} \alpha$, but those especially relevant to asthma include $\mathrm{T}$ lymphocytes, monocytes/macrophages, mast cells, eosinophils and epithelial cells. ${ }^{14}$ Importantly, $\mathrm{TNF} \alpha$ promotes recruitment of neutrophils, as well as eosinophils, into the airways through functional effects on the endothelium ${ }^{15}$ and by direct and indirect chemotactic effects. ${ }^{16}$ Recognising the unmet need in severe persistent asthma, we investigated the potential of $\mathrm{TNF} \alpha$ as a therapeutic target in this disease.

\section{METHODS}

The studies were approved by the Southampton and South West Hampshire local research ethics committees and volunteers gave their written informed consent.

\section{Clinical assessment and subject classification}

Healthy non-asthmatic subjects and mild asthmatic subjects were recruited from a research database of volunteers, and subjects with severe asthma were identified from outpatient clinics. Detailed clinical history and physical examination were performed on all subjects. Spirometric tests and assessment of asthma severity were in accordance with the BTS/SIGN guidelines. ${ }^{2}$ All subjects were tested for atopy by skin prick testing and were free from respiratory tract

Abbreviations: $\mathrm{BHR}$, bronchial hyperresponsiveness; $\mathrm{FEV}_{1}$, forced expiratory volume in 1 second; FVC, forced vital capacity; PEF, peak expiratory flow; TNF $\alpha$, tumour necrosis factor $\alpha$ 
Table 1 Subject details presented for the whole study group and for each separate study group

\begin{tabular}{|c|c|c|c|c|}
\hline $\begin{array}{l}\text { TNF } \alpha \text { study and } \\
\text { patient groups } \ddagger\end{array}$ & $\begin{array}{l}\text { Subject } \\
\text { numbers }\end{array}$ & $\operatorname{Sex}(M / F)$ & $\begin{array}{l}\text { Mean (range) age } \\
\text { (years) }\end{array}$ & $\begin{array}{l}\text { Mean (SE) FEV } \\
\text { (\% predicted) }\end{array}$ \\
\hline \multicolumn{5}{|l|}{ All subjects } \\
\hline Healthy controls & 26 & $8 / 18$ & $30.2(19-54)$ & $101.7(2.0)$ \\
\hline Mild asthma & 67 & $40 / 27$ & $30.0(18-57)$ & $90.4(1.4)^{\star *}$ \\
\hline Severe asthma & 51 & $15 / 36$ & $41.5(18-67)$ & $61.4(2.7)^{* * *}+\dagger$ \\
\hline \multicolumn{5}{|l|}{ Lavage studies } \\
\hline \multicolumn{5}{|l|}{ Comparator study } \\
\hline Healthy controls & 26 & $8 / 18$ & $30.2(19-54)$ & $101.7(2.0)$ \\
\hline Mild asthma & 42 & $24 / 18$ & $30.3(18-50)$ & $94.2(1.2)^{*}$ \\
\hline Severe asthma & 20 & $5 / 15$ & $39.6(18-67)$ & $55.8(4.3)^{* * *} \dagger$ \\
\hline \multicolumn{5}{|l|}{ Biopsy studies } \\
\hline \multicolumn{5}{|l|}{ Gene expression } \\
\hline Mild asthma & 14 & $7 / 7$ & $28.8(19-47)$ & $98.8(2.0)$ \\
\hline Severe asthma & 14 & $6 / 8$ & $44.5(20-67)$ & $59.4(6.0) \dagger$ \\
\hline \multicolumn{5}{|c|}{ Immunohistochemistry } \\
\hline Mild asthma & 42 & $25 / 17$ & $31.1(20-52)$ & $87.2(2.0)$ \\
\hline Severe asthma & 14 & $6 / 8$ & $38.0(18-67)$ & $48.8(3.1)+\dagger$ \\
\hline \multicolumn{5}{|l|}{ Etanercept study } \\
\hline Severe asthma & 17 & $5 / 12$ & $43(30-67)$ & $68.3(5.0)$ \\
\hline
\end{tabular}

Differences between the groups and the healthy control subjects with respect to $\mathrm{FEV}_{1} \%$ predicted are designated by ${ }^{*} \mathrm{p}<0.01,{ }^{* *} \mathrm{p}<0.001$ and ${ }^{* * *} \mathrm{p}<0.0001$, while differences for the same measure between the mild and severe asthmatic groups are indicated as $+p<0.001$ and $+1 p<0.0001$.

†The different subject groups were defined on the following basis:

(a) Healthy control subjects had no history or symptoms to suggest asthma, normal lung function and normal bronchial reactivity, as reflected by a $\mathrm{PC}_{20}$ methacholine of $>16 \mathrm{mg} / \mathrm{ml}$.

(b) Mild asthma was defined on the basis of a doctor diagnosis of asthma, current symptoms compatible with asthma, the need for the use of prn salbutamol for symptom relief but no other medication use for asthma.

(c) Severe asthma was defined on the basis of doctor diagnosed and treated asthma that remained symptomatic, despite treatment at stage $4 / 5$ of the BTS/SIGN guidelines, ${ }^{2}$ together with historical data of airway reversibility and the need for oral steroid therapy, either as regular maintenance therapy or for the treatment of exacerbations. Thirty seven of the 51 severe asthmatics were on maintenance oral steroid therapy for their disease control in addition to high dose inhaled steroids, long acting $\beta$ agonists, and additional treatment such as leukotriene receptor antagonists and theophyllines.

infections for a minimum of 4 weeks before inclusion in the study. The characteristics of the groups of subjects enrolled into the various arms of the study are summarised in table 1.

\section{Fibreoptic bronchoscopy}

Subjects underwent fibreoptic bronchoscopy under local anaesthesia as previously described ${ }^{17}$ using an Olympus BFIT20 bronchoscope (Olympus, Tokyo, Japan). Bronchoalveolar lavage (BAL) fluid was obtained by wedging the bronchoscope into a segmental bronchus and introducing six $20 \mathrm{ml}$ aliquots of $0.9 \%$ saline, pre-warmed to $37^{\circ} \mathrm{C}$. Gentle suction was used to collect the fluid into a $100 \mathrm{ml}$ plastic trap. The lavage fluid was centrifuged at $400 \mathrm{~g}$ for 10 minutes at $4^{\circ} \mathrm{C}$ and the supernatant aliquoted and stored at $-80^{\circ} \mathrm{C}$ until assayed for TNF $\alpha$. Bronchial biopsies were taken from the third or fourth airway carinae using Precisor Broncho pulmonary coated disposable biopsy forceps (Bard Endoscopic Technologies, Billerica, USA). These were either transferred immediately into ice cold acetone containing iodoacetamide $(20 \mathrm{nM})$ and phenylmethylsulfonylfluoride $\left(2 \mathrm{mM}\right.$ ) and placed at $-20^{\circ} \mathrm{C}$ for 24 hours before processing into glycol methacrylate resin (Polysciences, Northampton, UK) for embedding, ${ }^{18}$ or snap frozen in liquid nitrogen prior to RNA extraction.

\section{Immunodetection of TNFa}

BAL fluid was concentrated 10-30 fold using Amicon Centriprep YM-3 centrifugal filter devices (Millipore (UK) Ltd, Watford, UK) before measurement of TNF $\alpha$ by ELISA (R\&D Systems, Abingdon, Bucks, UK). The assay had a lower limit of detection of $60 \mathrm{fg} / \mathrm{ml}$ and a coefficient of variation of repeated measures of $3.4 \%$. Data are corrected for concentration and thus represent unconcentrated BAL fluid values.

Immunohistochemical staining for TNF $\alpha$ was conducted as previously described ${ }^{18}$ using a murine monoclonal antibody against human TNF $\alpha$ (1:500, R \& D Systems). The specificity of the antibody was confirmed by omitting the primary antibody and replacing it with an isotype matched antibody. The number of TNF $\alpha$ positive cells was determined by counting the total number of TNF $\alpha$ immunoreactive cells within the biopsy section, excluding areas of muscle, large blood vessels, glands, damaged tissue and artefact. Counts were made in two separate tissue sections cut at least $10 \mu \mathrm{m}$ apart, and the mean number of cells calculated. Only cells with an identifiable nucleus were counted. The area of the individual biopsy samples was measured using image analysis (Colorvision 1.7.6, Improvision, Coventry, UK), excluding those areas not included in the counting, and the data corrected to cells per $\mathrm{mm}^{2}$.

\section{TNF $\alpha$ mRNA expression}

For analysis of TNF $\alpha$ gene expression, total RNA was extracted from individual biopsy specimens. One microgram of total RNA was reverse transcribed using the reverse transcription (RT) System (Promega, Southampton, UK) according to the manufacturer's instructions. TNF $\alpha$ primer (Qiagen) and probe (Eurogentec, Seraing, Belgium) sequences labelled with a 5'-reporter dye FAM (6-carboxyfluorescin) and a $3^{\prime}$-Eclipse DARK quencher ${ }^{\mathrm{TM}}$ were: forward primer 5'-AAGAGGGAGAGAAGCAACTACAGA-3'; reverse primer 5'-GGTGGAGCCGTGGGTCAG-3'; and probe FAM-5'AACAACCCTCAGACGCCACATCCCCT-3'-Eclipse. Random hexamers were used to reverse transcribe total RNA as 18S ribosomal RNA (18S rRNA) was the endogenous control. For each duplicate sample the PCR reaction contained $25 \mathrm{ng}$ of cDNA template, $3.2 \mathrm{pM}$ fluorogenic probe, $15 \mathrm{pM}$ forward and reverse primers, and $7.5 \mu \mathrm{l}$ qPCR mix (Eurogentec) in a final volume of $12.5 \mu \mathrm{l}$. Separate normalising controls were run which contained $1 \mu \mathrm{l}$ of $18 \mathrm{~S}$ rRNA and probe mixes (Eurogentec). RT negative samples were used to indicate that 
the signals obtained were RT dependent. The PCR protocol was as follows: $95^{\circ} \mathrm{C}, 10$ minutes, followed by 40 cycles of denaturation $95^{\circ} \mathrm{C}, \quad 15$ seconds, and annealing/extension $60^{\circ} \mathrm{C}, 1$ minute. Thermocycling and real time detection of PCR products were performed on an iCyclerIQ sequence detection system (Bio-Rad, Hercules, CA, USA) and, following completion of the PCR reaction, the thresholds for fluorescence emission baseline were set automatically at 10 times the background levels on the FAM layer. Expression levels were normalised to the 18S rRNA levels and then expressed relative to the lowest expression value found in mild asthma using the $\Delta \Delta \mathrm{C}_{\mathrm{T}}$ method. Samples were measured in duplicate.

\section{Proof of principle clinical study evaluating the effect of etanercept in severe asthma}

Seventeen subjects ( 12 women) of median age 43 years (range 30-67) with a mean (SD) duration of asthma of 23.8 (11.7) years were enrolled into the trial. Their mean (SD) resting forced expiratory volume in 1 second $\left(\mathrm{FEV}_{1}\right)$ was 68.3 (5.0)\% predicted. These patients were similar to those studied in the bronchoalveolar lavage and biopsy studies, being at stage 5 of the BTS/SIGN asthma management guidelines, ${ }^{2}$ requiring treatment with high dose inhaled corticosteroids (equivalent to beclometasone $2500 \mu \mathrm{g} / \mathrm{day}$ ) and oral prednisolone (mean dose $11.5 \mathrm{mg} /$ day). In addition to long acting $\beta_{2}$ agonists, theophylline and leukotriene modifying drugs, all the subjects required prn salbutamol on an as required basis, delivered either by metered dose inhaler or by nebuliser. Current smokers, subjects with a smoking history of more than 10 pack years, and those with other coexisting lung diseases, a history of tuberculosis, multiple sclerosis, lupus erythematosus, and other autoimmune diseases were excluded.

Each patient received subcutaneous etanercept (Enbrel, Wyeth Laboratories, Berkshire, UK) $25 \mathrm{mg}$ twice weekly as add-on therapy for 12 weeks. The dose of medication and the duration of treatment were chosen from the initial trials of etanercept in rheumatoid arthritis. ${ }^{20}$ No change was made to their regular controller asthma medications during the 12 week treatment period and all reliever medications except bronchodilators were kept constant throughout the study.

The primary efficacy variable was improvement in asthma control and the secondary outcome measures were changes in airway hyperresponsiveness to inhaled methacholine and lung function. The manufacturer of etanercept had no involvement in the design of the study.

Subjective asthma control, as measured by the Juniper asthma control questionnaire, ${ }^{21}$ was recorded on entry and completion, together with morning and evening peak expiratory flow (PEF) using Wright mini peak flow meters (the best of three) recorded daily in diary cards. Adverse events during the study period and use of regular and rescue medication were also recorded. The clinic lung function was recorded as $\mathrm{FEV}_{1}$ and forced vital capacity (FVC) using a Vitalograph compact spirometer (Vitalograph Ltd, Maids Moreton, Bucks, UK). Spirometric tests were performed at baseline, on entry into the study, and at the end of the study as well as at a follow up visit 8 weeks after the last dose of the study drug.

Non-specific BHR was assessed before and at the end of week 12 of treatment with etanercept using the methacholine bronchial provocation test. ${ }^{22}$ The test was carried out in all subjects whose $\mathrm{FEV}_{1}$ was more than $50 \%$ predicted. Subjects were asked not to take their salbutamol (or other rescue bronchodilators) within at least 4 hours before the methacholine challenge. Nebulised methacholine (Sigma Co, Poole, Dorset, UK) dissolved in saline was administered through a dosimeter (Spira Electro 2, Spira, Finland) in doubling dilutions until the $\mathrm{FEV}_{1}$ fell by at least $20 \%$. The degree of airways responsiveness to methacholine was expressed as the cumulative $\mathrm{PC}_{20}$, as determined by linear interpolation..$^{22}$

Sputum induction was performed on all the subjects at baseline and after 12 weeks of treatment with etanercept according to the method of Pizzichini $e^{2} \mathrm{al}^{23}$ using inhalation of aerosolised hypertonic saline (4.5\%) for 20 minutes administered via an ultrasonic nebuliser (Devilbiss Ultraneb 2000, PA, USA). The procedure was discontinued when there was a fall in PEF of $>15 \%$ or if there were troublesome symptoms. Sputum processing involved adding an equal weight of $0.01 \mathrm{M}$ dithioerythritol, filtering through a $70 \mu \mathrm{m}$ filter, and centrifugation for 10 minutes at $400 \mathrm{~g}$ at $4{ }^{\circ} \mathrm{C}$. The cell pellet was resuspended in $1 \mathrm{ml}$ Tris-buffered saline (TBS) and cells were counted in a Neubauer's chamber after staining with trypan blue. Two cytospins per sample were processed using Rapi-Diff stain and 600 cells counted per cytospin, in a blinded fashion, to obtain differential cell counts; the mean value was used for analysis. The differential cell counts were expressed as the percentage of the total cells.

\section{Statistical analysis}

Paired $t$ test (mean (SE)) and Wilcoxon's signed rank tests (median, IQR) were used as appropriate for within group comparisons and non-paired comparator analyses with $t$ tests and Mann-Whitney U tests were used for between group comparisons. Statistical analysis was undertaken using SPSS for Windows version 11.5 (SPSS, Chicago, IL, USA).

\section{RESULTS}

\section{TNF $\alpha$ levels in BAL fluid and mRNA}

As the airway lumen is an important site of neutrophil accumulation in severe asthma, ${ }^{34}$ we first sought evidence for abnormal levels of TNF $\alpha$ in BAL fluid from asthmatic subjects with varying degrees of disease severity (table 1) and non-asthmatic controls. The severe asthmatics had significantly higher concentrations of TNF $\alpha$ (median $160 \mathrm{fg} / \mathrm{ml}$ (range 100-6660)) in BAL fluid than either the healthy controls $(117 \mathrm{fg} / \mathrm{ml}(64-301) \mathrm{p}=0.001)$ or those with mild asthma $(111 \mathrm{fg} / \mathrm{ml} \mathrm{(37-322),} \mathrm{p}<0.001)$; the difference between the latter two groups was not significantly different (fig 1A). Relative TNF $\alpha$ mRNA levels were also significantly higher in biopsy specimens from the severe asthmatic subjects (median 2617 (range 58-276 488)) compared with mild asthmatic subjects $(84(1-1282) ; p=0.002$, fig $1 B)$.

\section{TNFa levels in bronchial biopsy specimens}

To further identify the cellular source of TNF $\alpha$ protein, tissue sections of bronchial biopsies were examined by immunohistochemistry. This showed that TNF $\alpha$ expression was localised predominantly to mast cells, with occasional other cell types also showing some positive immunostaining. There were significantly greater numbers of $\mathrm{TNF} \alpha$ immunoreactive cells $/ \mathrm{mm}^{2}$ in biopsy specimens from subjects with severe asthma (median 5.6 (range 0-62)) than in those from subjects with mild asthma (median 2.5 (range $0-26$ ); $p<0.03$, fig $\mathrm{IC}$ and $\mathrm{D})$.

\section{Clinical study with etanercept}

Seventeen patients (table 1) with severe asthma who were symptomatic despite receiving maximum inhaled corticosteroids were recruited into the open label study and received etanercept as add-on therapy for 12 weeks. Two of the 17 subjects enrolled into the study failed to complete it, one because of a swelling in the neck that was subsequently identified as a lipoma and the second developed a skin rash with the first dose of etanercept and was not keen to continue in the trial despite the rash resolving spontaneously. 

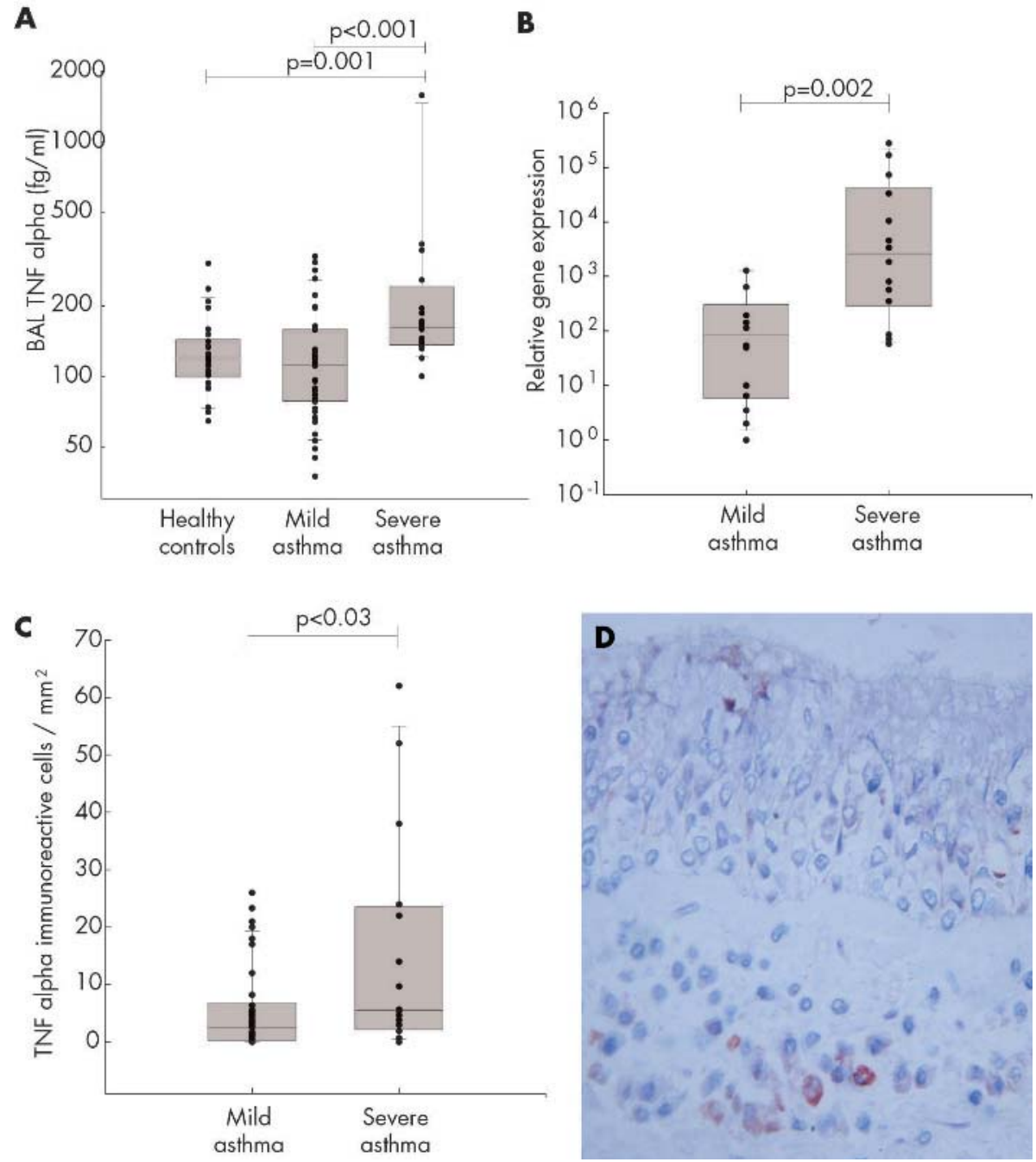

Figure 1 (A) TNF $\alpha$ concentrations in bronchoalveolar lavage (BAL) fluid from healthy control subjects $(n=26)$, subjects with non-steroid treated mild asthma $(n=42)$ and those with steroid treated severe asthma $(n=20)$. For presentation purposes, one outlier $(6660 \mathrm{fg} / \mathrm{ml})$ in the severe asthma group is omitted from the graph. TNF $\alpha$ was measured by ELISA. (B) TNF $\alpha$ gene expression in endobronchial biopsy specimens from 14 patients with mild asthma and 14 with severe asthma. Total RNA was extracted and analysed by reverse transcription quantitative PCR. Results are normalised to the $18 \mathrm{~S}$ rRNA levels and are presented as relative TNF $\alpha$ levels which were calculated using the $\Delta \Delta C_{T}$ method. (C) Immunoreactive TNF $\alpha$ positive cell counts in endobronchial biopsy specimens (cells $/ \mathrm{mm}^{2}$ ) from 42 subjects with mild asthma and 14 subjects with severe asthma. (D) Immunohistochemical staining and localisation of TNF $\alpha$ in submucosal cells in a bronchial biopsy specimen from a subject with severe asthma. The data in $A, B$ and $C$ are presented as box and whisker plots showing the median, interquartile range, and $95 \%$ confidence limits with individual data points superimposed. Data were analysed using the Mann-Whitney $\mathrm{U}$ test and significant differences are indicated.

The adverse events during etanercept treatment were mild (table 2).

Of the 15 subjects who completed the study, 12 weeks of treatment with etanercept resulted in a marked and highly

\begin{tabular}{|lc|}
\hline $\begin{array}{l}\text { Table } 2 \text { Adverse events during treatment with } \\
\text { etanercept }\end{array}$ \\
\hline Adverse events & No (\%) \\
\hline Skin rash & $6(35.3)$ \\
Respiratory tract infections & $10(58.8)$ \\
Asthma exacerbations & $9(52.9)$ \\
Injection site reactions & $4(23.5)$ \\
Oral thrush & $2(11.2)$ \\
Joint pains & $1(5.9)$ \\
Nose bleed & $1(5.9)$ \\
Positive antinuclear antibody & $3(17.6)$ \\
\hline
\end{tabular}

significant improvement in symptoms with the mean (range) asthma control questionnaire score falling from 26 (9-32) to 11 (4-27), p<0.001 (fig 2A). This was accompanied by a significant increase in baseline $\mathrm{FEV}_{1}, \mathrm{FVC}$, and morning and evening PEF (table 3), and all but one of the patients discontinued their use of nebulised $\beta_{2}$ agonist. Of particular significance was the effect of etanercept in reducing BHR, with the provocative concentration of methacholine producing a $20 \%$ decrease in $\mathrm{FEV}_{1}\left(\mathrm{PC}_{20}\right)$ increasing from a geometric mean of $0.21(0.1-0.64) \mathrm{mg} / \mathrm{ml}$ to 1.28 (0.53$2.92) \mathrm{mg} / \mathrm{ml}$ (fig $2 \mathrm{~B}$ ), representing a change of 2.5 doubling dilutions (table 3). Eight weeks after stopping etanercept, symptom scores and lung function had returned to pretreatment values.

Despite the severity of their asthma, we were able to obtain paired sputum samples from 11 of the 15 subjects involved in the study. However, although reductions in eosinophil and neutrophil numbers were observed in eight of the 11 subjects, this failed to achieve statistical significance. 

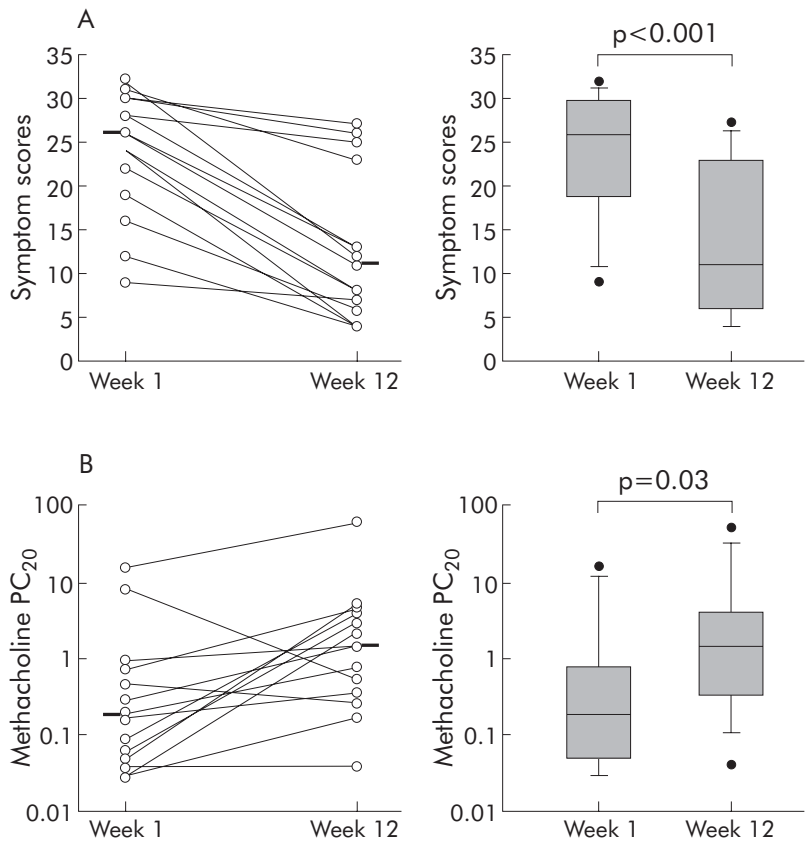

Figure 2 (A) Symptom scores before and after treatment in 15 corticosteroid dependent severe asthmatic subjects treated with etanercept $25 \mathrm{mg}$ twice weekly for 12 weeks. (B) Concentration of methacholine required to reduce $\mathrm{FEV}_{1}$ by $20 \%$ of baseline $\left(\mathrm{PC}_{20}\right)$ at weeks 1 and 12 as a measure of the effect of etanercept on bronchial reactivity. Data are shown as paired data before and after treatment with median (panel A) or geometric mean (panel B) indicated (left hand panels); the box and whisker plots (right hand panel) show median (panel A) or geometric mean (panel B), interquartile range and 5-95\% confidence intervals with outliers shown as dots. Statistical significances were determined using the Wilcoxon rank sum test.

\section{DISCUSSION}

Although asthma is considered an eosinophilic disorder, ${ }^{1}$ at the severe end of the disease spectrum there is an altered inflammatory cell profile involving neutrophils. ${ }^{3}{ }^{4}$ Consistent with this predominance of neutrophils, ${ }^{3}{ }^{4}$ we have shown that patients with severe corticosteroid dependent asthma have higher concentrations of TNF $\alpha$ in recovered BAL fluid. In contrast, no difference was seen between BAL fluid TNF $\alpha$ concentrations in mild asthmatics and healthy controls. This suggests that the increase in TNF $\alpha$ seen in subjects with severe disease is a feature of more persistent and corticosteroid refractory asthma rather than of asthma per se. This extends previous reports in which increased TNF $\alpha$ concentrations have been reported in BAL fluid in symptomatic asthma ${ }^{24}$ and in those ventilated because of acute severe disease. ${ }^{25}$ We also found greater numbers of TNF $\alpha$ immunoreactive positive cells and greater gene expression for TNF $\alpha$ in endobronchial biopsy specimens from subjects with severe asthma than from those with symptomatic non-steroid treated asthma. As we have previously reported in biopsies from mild asthma, ${ }^{19}$ this TNF $\alpha$ was localised predominantly to mast cell granules. Our findings in severe asthma were evident despite treatment with high dose inhaled corticosteroids and, in the majority, with additional oral corticosteroid therapy. Thus, not only is $\mathrm{TNF} \alpha$ overexpressed within the airways of patients with severe disease, but current optimal treatment does not resolve this.

The therapeutic options for patients with corticosteroid dependent asthma are limited. These patients represent a clinical burden accounting for approximately 30\% of the healthcare costs of asthma through multiple hospital admissions for exacerbations and the side effects of long term corticosteroids. ${ }^{5}$ In other disease areas the appreciation that anti-TNF $\alpha$ strategies are able to modify disease that persists despite corticosteroid therapy led us to consider the potential benefit of anti-TNF $\alpha$ intervention strategies in the severe asthmatic group. We opted to use etanercept, which binds specifically to both TNF $\alpha$ and TNF $\beta$ thereby preventing free cytokine binding to cell surface TNF receptors. ${ }^{26}$ This was a proof of concept study and, as such, was open labelled and uncontrolled.

Etanercept treatment was associated with improvement in asthma symptoms, lung function, and BHR. It is unlikely that such changes would have arisen by chance in view of the chronic and persistent nature of the disease in these patients. However, the study cannot be considered conclusive as it was an open labelled study. Despite maximum doses of inhaled and oral corticosteroids, regular treatment with etanercept produced remarkable improvements in both clinical and physiological measures of asthma. The most striking feature was the improvement in BHR. When measuring BHR in asthma using repeated methacholine challenge, it is accepted that the error in $\mathrm{PC}_{20}$ determination is within one doubling dilution. Following experimental allergen exposure or natural allergen exposure, changes of 1-2 doubling dilutions in $\mathrm{PC}_{20}$ are considered clinically significant. ${ }^{27}$ Thus, although we had no data on which to base a power calculation before starting the study, our findings of an improvement of 2.5 doubling dilutions in $\mathrm{PC}_{20}$ is well outside the natural variation and consistent with a significant clinical improvement, in addition to any beneficial effect that may have already been achieved using inhaled and oral corticosteroids. At the end of the study the beneficial effects of etanercept were maintained for 2-4 weeks before asthma symptoms gradually returned to the pretreatment state.

The most common adverse effects encountered with etanercept were injection site reactions. The respiratory tract infections experienced by the four subjects would not be unusual in such patients with severe disease. It is difficult to suggest a causal association between the respiratory tract infections and the study medication as this was an open labelled study. The infections were associated with worsening of asthma control which was managed by increasing the dose of rescue medications. However, none of the subjects needed an increase in either their oral or inhaled corticosteroids,

Table 3 Changes in lung function before and after treatment with etanercept

\begin{tabular}{|c|c|c|c|c|}
\hline & Before treatment & After treatment & $\begin{array}{l}\text { Mean change from } \\
\text { baseline }\end{array}$ & $p$ value \\
\hline $\mathrm{FEV}_{1}$ (I) & $1.91(0.5)$ & $2.16(0.6)$ & $0.24(0.18)$ & 0.01 \\
\hline FVC (I) & $2.55(0.2)$ & $2.88(0.2)$ & $0.33(0.29)$ & 0.03 \\
\hline Morning PEF (predicted \%) & $54.8(5.6)$ & $61.0(5.8)$ & $5.75(5.65)$ & 0.023 \\
\hline Evening PEF (predicted \%) & $55.3(5.1)$ & $63.9(5.1)$ & $8.04(5.23)$ & 0.005 \\
\hline Methacholine $\mathrm{PC}_{20}(\mathrm{mg} / \mathrm{mll})^{*}$ & $0.21(0.1$ to 0.64$)$ & 1.28 (0.53 to 2.92 ) & $2.5(1.75) \dagger$ & 0.033 \\
\hline
\end{tabular}

All values are mean (SE) except * ${ }^{*}$ eoometric mean $(95 \% \mathrm{Cl})$.

†Change shown as doubling dilutions of methacholine. 
suggesting a possible beneficial effect of etanercept in these subjects. Controlled studies have shown that only $2 \%$ of patients with rheumatoid arthritis became antibody positive when treated with etanercept, ${ }^{28}$ so we did not evaluate the occurrence of antibodies in our study group. However, since immunogenicity appears to be associated with an increased incidence of infusion reactions and a shortened duration of clinical response, this needs to be investigated in larger studies.

An important target for TNF $\alpha$ is the microvascular endothelium with upregulation of adhesion molecules such as ICAM-1 and VCAM-1 and enhancing leucocyte migration and activation. ${ }^{15}$ We attempted to study the effects of etanercept on indices of inflammation using induced sputum. Although reductions in eosinophil and neutrophil numbers were observed in eight of the 11 subjects, this failed to achieve statistical significance. While this may have arisen by chance, our data raise the possibility that the beneficial effects of etanercept were unrelated to inhibition of inflammatory cell recruitment. However, the observation that inhaled TNF $\alpha$ increases BHR and leucocyte influx into human airways ${ }^{12}{ }^{13}$ suggests that further studies involving tissue biopsies before and after therapeutic intervention may better address the effects of etanercept on endothelial cell activation and inflammatory cell recruitment.

Although etanercept and the anti-TNF $\alpha$ antibody infliximab both show powerful TNF $\alpha$ neutralisation, only infliximab is able to bind lamina propria $\mathrm{T}$ cells and induce apoptosis of activated lymphocytes in Crohn's disease. ${ }^{29}$ We therefore believe it is unlikely that the beneficial effect of entanercept in severe asthma involves regulation of $\mathrm{T}$ cells. Since we found that the predominant cells that expressed $\mathrm{TNF} \alpha$ in the airway biopsies were mast cells, at least some of the beneficial effects of etanercept are likely to relate to mast cell function. These cells selectively accumulate within the airways smooth muscle in asthma ${ }^{30}$ where the local release of TNF $\alpha$ can affect smooth muscle reactivity by increasing transcription of $\mathrm{G}_{\mathrm{i}} \cdot{ }^{31}$ As mast cell expression of TNF $\alpha$ is insensitive to inhibition by corticosteroids, ${ }^{32}$ its effect on smooth muscle function to cause $\mathrm{BHR}^{13}$ may be critical in maintaining persistent disease expression in chronic asthma. The modification of BHR by entanercept is therefore likely to be important in contributing to the clinical improvement. BHR is a fundamental physiological abnormality in asthma and, as corticosteroid insensitive BHR is a characteristic feature of severe disease, ${ }^{43}$ identification of a therapeutic intervention that reduces this is of major significance.

In summary, our study provides further evidence for a role for $\mathrm{TNF} \alpha$ in severe asthma and is the first study to evaluate the effects of TNF blockade in patients with severe asthma. While TNF $\alpha$ may well play a part in the less severe forms of asthma associated with allergen exposure, the dominance of Th2 mediated effects in this subtype of disease suggests that TNF $\alpha$ blockade may not be so effective. There is now a need for large placebo controlled trials using both the soluble receptor and antibody approaches to blocking TNF $\alpha$ with a focus on severe corticosteroid dependent asthma, where there remains a large unmet clinical need.

\section{ACKNOWLEDGEMENTS}

The authors thank Miss Lorraine Hewitt for providing nursing care in association with bronchoscopies and Dr Rob M Powell who provided probe and primer sequences for TNF $\alpha$ quantitative PCR.

\footnotetext{
Authors' affiliations

P H Howarth, K S Babu, H S Arshad, L Lau, M Buckley, W McConnell, P Beckett, M Al Ali, S J Wilson, D E Davies, S T Holgate, Allergy and Inflammation Research, Division of Infection, Inflammation and Repair, School of Medicine, Southampton General Hospital, Southampton, UK
}

A Chauhan, St Mary's Hospital, Respiratory Medicine, Portsmouth, UK A Reynolds, Wyeth Laboratories, Taplow, Maidenhead, Berkshire, UK

This work was supported by the Medical Research Council (UK) and an educational grant from Immunex (Amgen).

Competing interests: The proof of principle trial with etanercept was an investigator initiated study that was designed, executed, and analysed without input from any pharmaceutical company. Immunex (Amgen) provided an educational grant that contributed to the costs and Wyeth provided the etanercept without charge. The authors have no other competing interests to declare.

$\mathrm{PHH}$ and KSB contributed equally to this work.

\section{REFERENCES}

1 Kay AB. Allergy and allergic diseases. First of two parts. N Engl J Med 2001:344:30-7.

2 British Thoracic Society/Scottish Intercollegiate Guidelines Network. British guidelines on the management of asthma. Thorax 2003;58(Suppl I): 1-94

3 Busse WW, Banks-Schlegel S, Wenzel SE. Pathophysiology of severe asthma. J Allergy Clin Immunol 2000;106:1033-42.

4 Anon. The ENFUMOSA cross sectional European multicentre study of the clinical phenotype of chronic severe asthma. Eur Respir J 2003;22:470-7.

5 Antonicelli L, Bucca C, Neri M, et al. Asthma severity and medical resource utilisation. Eur Respir J 2004;23:723-9.

6 Feldmann M, Maini RN. Lasker Clinical Medical Research Award. TNF defined as a therapeutic target for rheumatoid arthritis and other autoimmune diseases. Nat Med 2003;9:1245-50.

7 Rudmann DG, Moore MW, Tepper JS, et al. Modulation of allergic inflammation in mice deficient in TNF receptors. Am J Physiol Lung Cell Mol Physiol 2000;279:L1047-57.

8 Zuany-Amorim C, Manlius C, Dalum I, et al. Induction of TNF-alpha autoantibody production by AutoVac TNF106: a novel therapeutic approach for the treatment of allergic diseases. Int Arch Allergy Immunol 2004; 133:154-63.

9 Li Kam Wa TC, Mansur AH, Britton J, et al. Association between -308 tumour necrosis factor promoter polymorphism and bronchial hyperreactivity in asthma. Clin Exp Allergy 1999;29:1204-8.

10 Noguchi E, Yokouchi Y, Shibasaki M, et al. Association between TNF $\alpha$ polymorphism and the development of asthma in the Japanese population. Am J Respir Crit Care Med 2002;166:43-6.

11 Kips JC, Tavernier J, Pauwels RA. Tumor necrosis factor causes bronchial hyperresponsiveness in rats. Am Rev Respir Dis 1992;145:332-6.

12 Thomas PS, Yates DH, Barnes PJ. Tumor necrosis factor-alpha increases airway responsiveness and sputum neutrophilia in normal human subjects. Am J Respir Crit Care Med 1995; 152:76-80.

13 Thomas PS, Heywood G. Effects of inhaled tumour necrosis factor alpha in subjects with mild asthma. Thorax 2002;57:774-8.

14 Thomas PS. Tumour necrosis factor-alpha: the role of this multifunctional cytokine in asthma. Immunol Cell Biol 2001;79:132-40.

15 Ulbrich H, Eriksson EE, Lindbom L. Leukocyte and endothelial cell adhesion molecules as targets for therapeutic interventions in inflammatory disease. Trends Pharmacol Sci 2003;24:640-7.

16 Ming WJ, Bersani L, Mantovani A. Tumor necrosis factor is chemotactic for monocytes and polymorphonuclear leukocytes. J Immunol 1987; 138:1469-74.

17 Diukanovic R, Wilson JW, Lai CK, et al. The safety aspects of fiberoptic bronchoscopy, bronchoalveolar lavage, and endobronchial biopsy in asthma. Am Rev Respir Dis 1991; 143:772-7.

18 Britten KM, Howarth PH, Roche WR. Immunohistochemistry on resin sections: a comparison of resin embedding techniques for small mucosal biopsies. Biotech Histochem 1993:68:271-80.

19 Bradding P, Roberts JA, Britten KM, et al. Interleukin-4, -5 , and -6 and tumor necrosis factor-alpha in normal and asthmatic airways: evidence for the human mast cell as a source of these cytokines. Am J Respir Cell Mol Biol 1994; 10:471-80.

20 Weinblatt ME, Kremer JM, Bankhurst AD, et al. A trial of etanercept, a recombinant tumor necrosis factor receptor:Fc fusion protein, in patients with rheumatoid arthritis receiving methotrexate. $N$ Engl J Med 1999;340:253-9.

21 Juniper EF, O'Byrne PM, Guyatt GH, et al. Development and validation of a questionnaire to measure asthma control. Eur Respir J 1999;14:902-7.

22 Chai H, Farr RS, Froehlich LA, et al. Standardization of bronchial inhalation challenge procedures. J Allergy Clin Immunol 1975;56:323-7

23 Pizzichini E, Pizzichini MM, Kidney JC, et al. Induced sputum, bronchoalveolar lavage and blood from mild asthmatics: inflammatory cells, lymphocyte subsets and soluble markers compared. Eur Respir J 1998; 11:828-34

24 Broide DH, Lotz M, Cuomo AJ, et al. Cytokines in symptomatic asthma airways. J Allergy Clin Immunol 1992;89:958-67.

25 Tillie-Leblond I, Pugin J, Marquette $\mathrm{CH}$, et al. Balance between proinflammatory cytokines and their inhibitors in bronchial lavage from patients with status asthmaticus. Am J Respir Crit Care Med 1999; 159:487-94.

26 Culy CR, Keating GM. Etanercept: an updated review of its use in rheumatoid arthritis, psoriatic arthritis and juvenile rheumatoid arthritis. Drugs 2002;62:2493-537. 
27 O’Byrne PM, Inman MD. Airway hyperresponsiveness. Chest 2003;123:41 1-6S.

28 Anderson PJ. Tumor necrosis factor inhibitors: clinical implications of their different immunogenicity profiles. Semin Arthritis Rheum 2005;34:19-22.

29 Van Den Brande JM, Braat H, Van Den Brink GR, et al. Infliximab but not etanercept induces apoptosis in lamina propria T-lymphocytes from patients with Crohn's disease. Gastroenterology 2003;124:1774-85.

30 Brightling CE, Bradding P, Symon FA, et al. Mast-cell infiltration of airway smooth muscle in asthma. N Engl J Med 2002;346:1699-705.
31 Hotta K, Hirshman CA Emala CW. TNF- $\alpha$ increases transcription of $\mathrm{G} \alpha(\mathrm{i}-2)$ in human airway smooth muscle cells. Am J Physiol Lung Cell Mol Physiol 2000;279:L319-25

32 Koranteng RD, Swindle EJ, Davis BJ, et al. Differential regulation of mast cell cytokines by both dexamethasone and the p38 mitogen-activated protein kinase (MAPK) inhibitor SB203580. Clin Exp Immunol 2004:137:81-7.

33 ten Brinke A, Zwinderman AH, Sterk PJ, et al. Factors associated with persistent airflow limitation in severe asthma. Am J Respir Crit Care Med $2001 ; 164: 744-8$

\section{LUNG ALERT}

A serum marker for the activity of pulmonary fibrosis in patients with systemic sclerosis

$\Delta$ Kodera M, Hasegawa M, Komura K, et al. Serum pulmonary and activation regulated chemokine/CCL18 levels in patients with systemic sclerosis. Arthritis Rheum 2005;52:2889-96

A ssessing the activity of pulmonary fibrosis in patients with systemic sclerosis requires both bronchoalveolar lavage and serial high resolution computed tomography. A blood test for the diagnosis and monitoring of pulmonary fibrosis would be simpler and less invasive. Serum levels of KL-6 and SP-D show some correlation with severity and activity of disease, but are not particularly reliable. The authors assessed the usefulness of measuring serum levels of pulmonary and activation regulated chemokine (PARC). PARC is expressed at high levels in bronchoalveolar lavage fluid in patients with systemic sclerosis who have pulmonary fibrosis. It may be a marker of immune mediated fibrotic lung disease.

Serum levels of PARC were measured in 123 patients with systemic sclerosis and compared with levels in healthy controls and in patients with systemic lupus erythematosus. PARC levels were significantly higher in the systemic sclerosis group. In a retrospective longitudinal study, serum levels of PARC, KL-6 and SP-D were measured in 21 patients during active and inactive phases of pulmonary fibrosis. Of the three blood tests, PARC levels were found to reflect disease activity most accurately.

This paper does not evaluate the sensitivity of the PARC test in making a diagnosis of pulmonary fibrosis. It does, however, indicate that PARC may be useful in monitoring disease activity in established disease. It should be noted that PARC is not specific for pulmonary fibrosis in systemic sclerosis. Further analysis with a larger number of subjects is indicated.

A H N Gerratt

SHO in Respiratory Medicine, Hillingdon Hospital, Uxbridge, UK; AnnaGerratt@doctors.org.uk 